
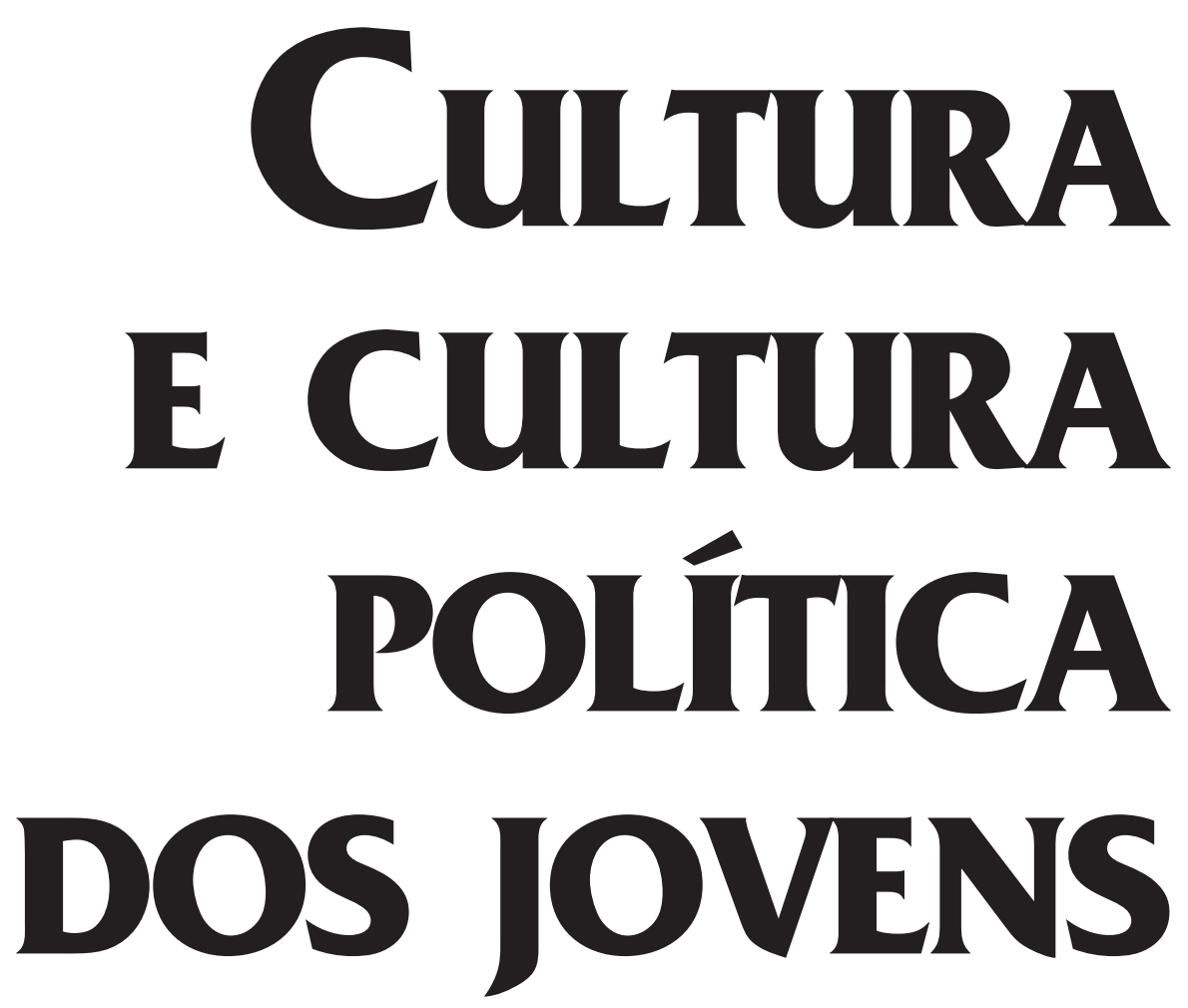

TEIXEIRA C OE L H O

\section{TEIXEIRA COELHO}

é coordenador

do Observatório

de Políticas Culturais

da Universidade de São

Paulo e autor, entre

outros livros, de Os

Histéricos, em

colaboração com Jean-

Claude Bernardet

(Companhia das Letras).

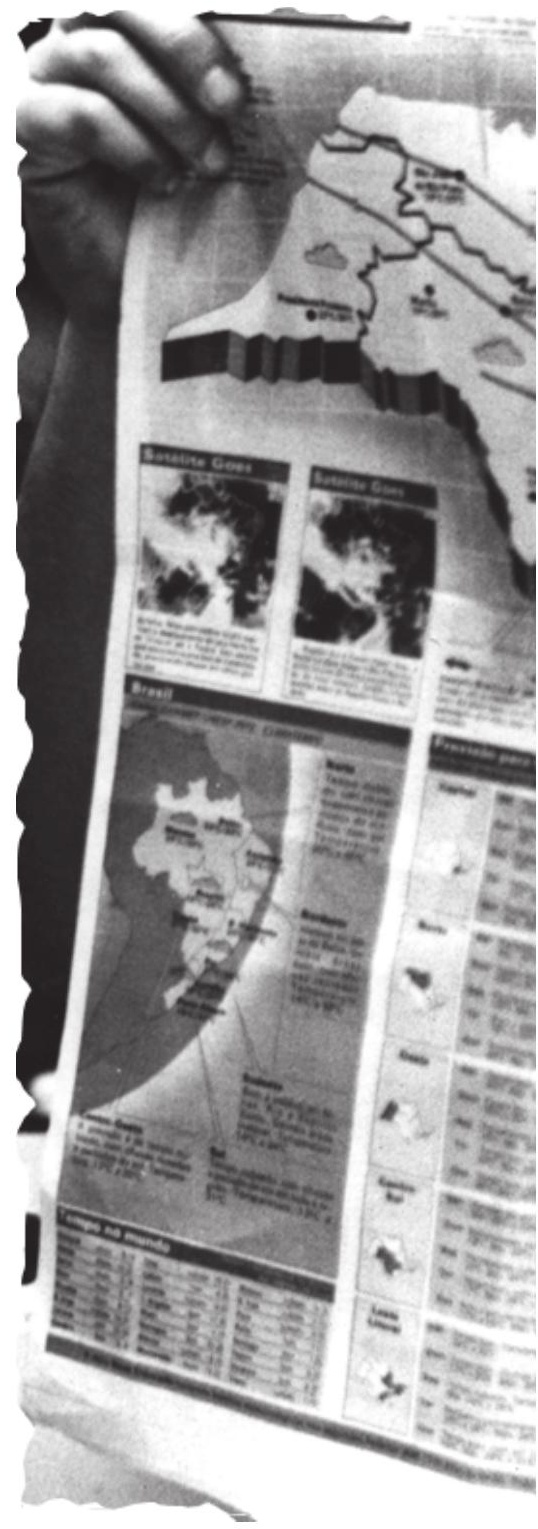

Pesquisa realizada em 1995 pelo Observatório de Políticas Culturais, ECA-USP sob a coordenação deste autor, publicada nos Cadernos do Observatório, no 1 , maio de 1996.

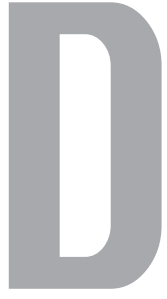

os jovens que, a partir dos 17 anos, conseguem sua admissão na Universidade de São Paulo, somente menos de 4\% declaram não ler jornais (1). Quase 50\% deles os lêem diariamente. A primeira seção que abrem não é a do noticiário geral, nem a de assuntos nacionais ou internacionais, menos ainda a de política: é o caderno de cultura, seguido pelas páginas de esportes. Somente num terceiro momento consultam as notícias políticas; e os que o fazem representam apenas 1/3 daqueles que lêem sobre cultura (pouco mais de 10\% do total). Quando esses estudantes saem da universidade, quatro ou cinco anos depois, o número dos que não lêem jornais sobe para $10 \%$ e os que os lêem diariamente são agora menos de $40 \%$. A ordem das leituras também se altera. Não em relação à primeira alternativa, 
exames de ingresso, da necessidade de se informarem pelos jornais sobre a realidade política, e não só ela, se quisessem ter condições de aprovação no vestibular. Como é grande a disparidade entre as opções pela cultura e pela política (30 pontos percentuais no caso dos ingressantes separam as duas opções, contra 40 pontos no quadro dos formandos), não é improvável que a atração do jovem, universitário ou não, pela informação cultural seja espontânea e corresponda a algum desejo mais enraizado enquanto a manifestada pela política mostre-se claramente induzida por um interesse imediato: ser aceito na universidade.

A rarefação das estatísticas sobre cultura no Brasil não permite que se façam comparações entre coisas iguais. Mas, apesar das cautelas necessárias, um paralelo com dados de algum modo convergentes com os obtidos nesta pesquisa sobre os estudantes da maior universidade brasileira corrobora as tendências entre eles observadas. Assim, uma pesquisa de âmbito nacional (2) realizada em 1993 por um instituto privado de sondagens, Ibope, dizia que $82 \%$ da população brasileira não confiava em políticos, $76 \%$ desconfiava dos partidos políticos, $60 \%$ rejeitava o Congresso Nacional e $45 \%$ afirmava não se interessar por política - apesar de $54 \%$ acreditar ser essencial, para o funcionamento da democracia, o trabalho dos congressistas. A política é considerada importante sem que, por isso, ela mesma e seus praticantes despertem adesão ou simpatia.

Voltando aos estudantes da Universidade de São Paulo, e agora aos estudantes de sociologia em particular, uma outra pesquisa de 1995 (3) aponta para o fato de apenas $13 \%$ (ou seria o caso de dizer, considerando-se o atual quadro político no país, o número surpreendentemente alto de $13 \%$ ?) estarem ligados de alguma forma a partidos políticos enquanto um número praticamente igual, $12 \%$, pertence a grupos religiosos e $28 \%$ a clubes esportivos ou de lazer (7\% participam de ONGs e 3\%, de associações cívicas). Ajuda muito a leitura destes índices verificar que o índice de participação desses estudantes em grupos políticos cai decididamente à medida que avançam os anos 90: era de $19 \%$ em 91 e caiu para $10 \%$ em 95, enquanto a adesão a grupos religiosos, depois de uma inflexão no biênio $92-$ 93, voltou a crescer fortemente a partir de 94 (de $19 \%$ para $4 \%$ e depois para $8 \%$ e $16 \%$ ). Indagados a respeito das pessoas nas quais mais confiam, estes mesmos sociólogos em embrião indicaram em primeiro lugar os parentes e os amigos (90\%), depois seus professores (mas apenas com 30\%...), enquanto personagens da vida pública aparecem em último lugar (com 23\%). Não causa estranheza, então, que $70 \%$ da população nacional (4) seja favorável à extinção do voto obrigatório. Este último dado, que poderia surgir como sinal de maturidade política, pede para ser examinado como indício de exaustão de um modelo. Confirmam essa interpretação dados que vêm um pouco de toda parte, como uma sondagem feita no Rio de Janeiro entre os alunos da Escola Nacional de Ciências Estatísticas mantida pelo IBGE, Instituto Brasileiro de Geografia e Estatística(5). Essa pesquisa numericamente significativa, cobrindo mais da metade dos alunos da escola-com a mesma idade genérica dos estudantes da USP, porém com uma diferença: enquanto os da USP podem ser considerados, na maioria, representantes das classes médias, os do Rio emergem das camadas eufemisticamente ditas populares -, revela que também entre esses jovens impera uma forte descrença quanto aos métodos, propósitos e resultados da política.

Para ser percebido em todo seu sentido, este perfil dos jovens deve ser examinado sob um ângulo específico. Depois de uma inflexão na camada da pirâmide etária ocupada pelos jovens - que levou a considerarse prematuramente o Brasil como um país em envelhecimento -, as projeções estatísticas indicam uma ampliação importante, ao longo da década de 90, do segmento daqueles situados entre os 15 e os 24 anos. Esses jovens, com essas sensações e estados de espírito diante da vida política (e do valor do trabalho, da violência e das injustiças sociais), irão num futuro imediato pesar numericamente, e qualitativamente, sobre o quadro da opinião nacional, sobre a representação que os brasileiros fazem de suas condi- 
ções de existência. Uma rede de indiferença e repulsa diante da política tende a se espraiar, facilitando a ocupação do poder por grupos de interesses estritamente particulares legais, semilegais e ilegais. Esse grupo etário que tende a pesar estatisticamente no quadro nacional é, ainda, o mesmo grupo mais exposto à exclusão social em suas diferentes formas-econômica, laboral, política e existencial - e à auto-exclusão.

Todos esses dados confirmam as investigações recentes que apontam para o declínio do prestígio das instituições em geral, incluindo as políticas, e para o deslocamento das atenções e interesses do campo dos argumentos racionais para o terreno das especulações místicas, como indica a distribuição praticamente idêntica dos estudantes de sociologia entre os agrupamentos políticos e os religiosos. Essa atitude era invisível há trinta anos, quando os fatos políticos relevantes foram acionados majoritariamente pelos jovens universitários revoltados, quer dizer, pelos jovens que calculavam e que num segundo momento, à força de tanto calcular, começaram a querer sentir, primeiro esteticamente, como se viu ao final daqueles mesmos anos 60 e início dos
70, e agora misticamente.

Esse tipo de observação, recorrente na análise de pesquisadores ditos pós-modernos, não é para ser entendido de modo necessariamente apocalíptico. A idéia do político, da coisa política, não está morta entre os jovens, talvez se mostre apenas sob outra forma - na verdade, uma forma entre eles recorrente. Estaria em declínio a política entendida tradicionalmente e, em ascensão, um modo urbano da política: a política enquanto relação de convivência na cidade (apesar da violência), a política enquanto estar junto, enquanto socialidade (6). A pesquisa com os estudantes da USP mostrou que, se é expressivo o número daqueles que em seu tempo livre optam pelas práticas culturais tradicionalmente entendidas (ir ao cinema ou ao teatro, assistir a um espetáculo musical), um número ainda mais significativo prefere as práticas societais, aquelas relacionadas aos modos de estar junto: sair com amigos, conversar com amigos ou, mesmo, ficar em casa com amigos ou com a família. E a distância entre as práticas culturais e as societais, em favor destas, torna-se mais acentuada entre os formandos, que se dedicam ainda menos à "cultura" do que os
6 Michael Maffesoli, A Contemplação do Mundo, Porto Alegre, Oficina, 1995

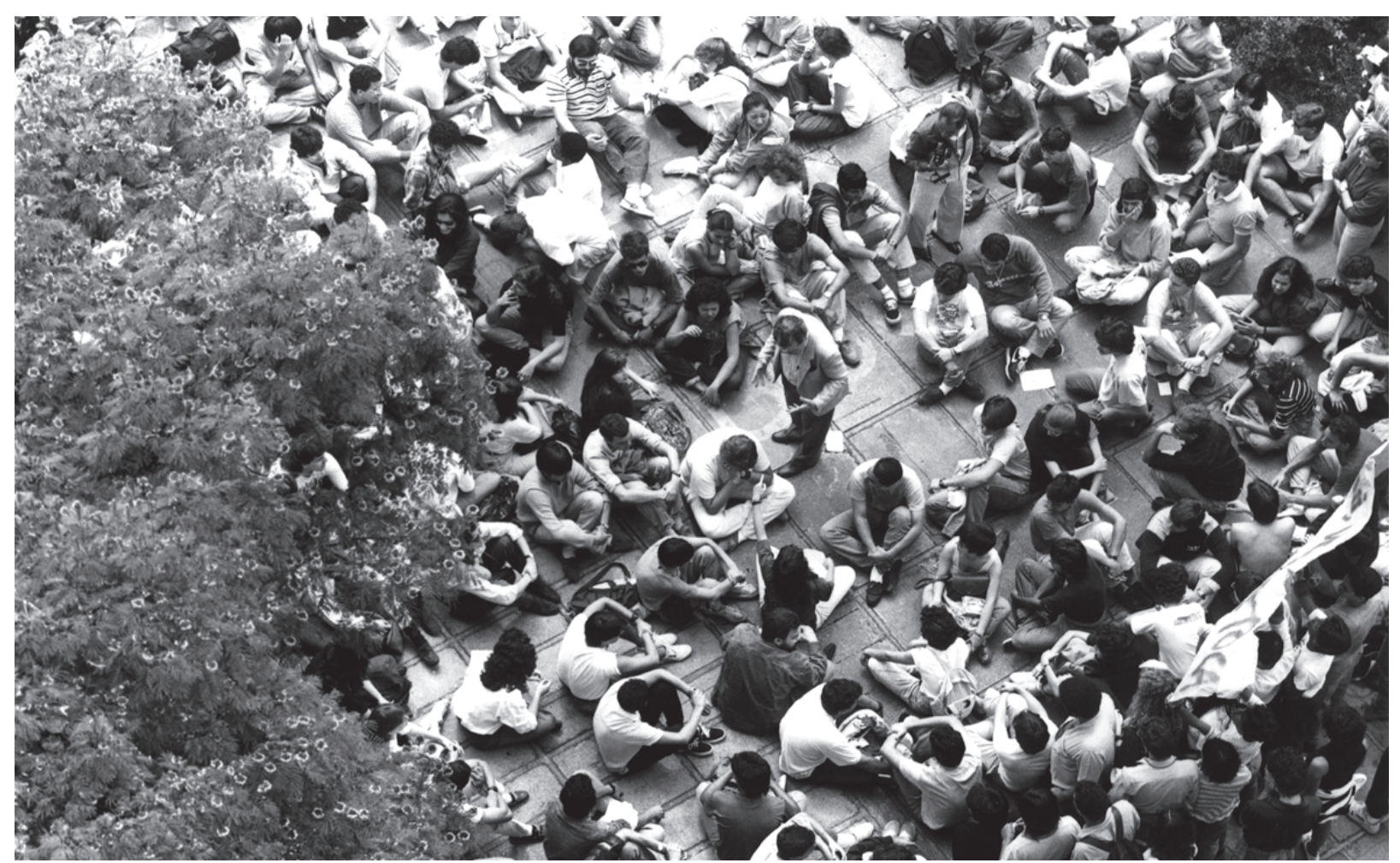




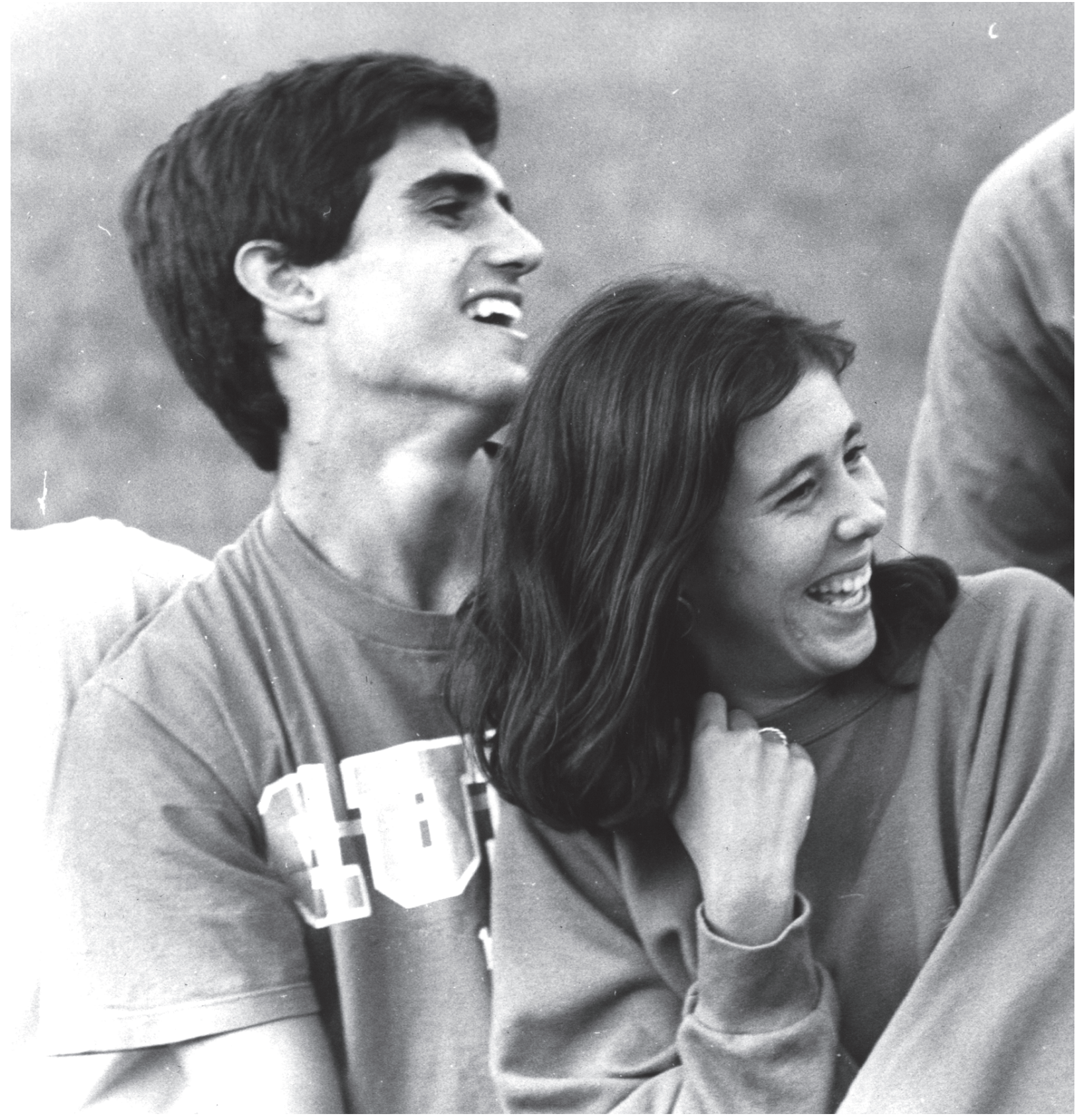

calouros e bem mais à convivência. Esta é a tendência igualmente dos jovens franceses, que optariam ainda mais maciçamente do que os brasileiros pela socialidade em detrimento da culturalidade (7), ao contrário do que poderiam fazer pensar os velhos clichês sobre o vigor da cultura formal nesse país europeu. E se os formandos da USP lêem menos sobre política nos jornais, em contrapartida interessam-se muito mais do que os calouros pelos assuntos de sua cidade e lêem muito mais jornais de bairro do que os calouros, o que parece confirmar seu interesse e preocupação por uma inserção no universo que mais de perto lhes diz respeito.

Essa socialidade - e não mais o social, legado do século XIX - revela um traço importante para a compreensão de um eventual "novo estatuto político": as relações preferidas pelos jovens são as que se dão de modo direto e imediato, sem a mediação de alguma coisa ou objeto como a obra de cultura, eventual pretexto para a troca simbólica, e sem a mediação de um agente, como no quadro político-institucional tradicional. O 
que parece interessar-lhes mais é o que está a seu redor imediato, ao alcance da vista e do corpo. Esse traço do comportamento jovem reforça outra tese com circulação atual, a da decadência das idéias de delegação e representação, base da forma política republicana clássica. Se metade da população brasileira reconhece que o funcionamento do Congresso é importante para a democracia ao mesmo tempo em que $82 \%$ dessa população não confia em políticos, não é improvável que a idéia da coisa política, da ação política, da participação política seja aceitável se essa política puder ser exercida sem mediação ou de outra forma. Ou, em todo caso, sem a mediação política institucionalizada na forma de delegação de poderes e representação das vontades. James Fishkin (8), da Universidade do Texas, em Austin, não será um pensador pós-moderno adepto das idéias do fim das instituições. No entanto, é convergente com a análise pós-moderna sua conclusão de que os governos perderam contato com a "voz do povo", submersa numa massa informe de eleições (as pessoas não recordam os nomes dos candidatos em que votaram um ou dois anos antes), ações lobistas e sondagens de opinião superficiais e dirigidas. Vindo de outra origem, James Fishkin fala, ele também, no retorno da idéia de uma "democracia deliberativa" que poderia ser eventualmente alcançada através de "sondagens deliberativas". Em julho de 1996, Fishkin conduziu uma dessas sondagens na Inglaterra sobre o futuro da monarquia. Trezentas pessoas, escolhidas ao acaso através do país, foram reunidas durante três dias. Em vez de responderem a um questionário previamente preparado sobre suas idéias relativas ao tema, ouviram e debateram as idéias de políticos, jornalistas e peritos em assuntos constitucionais relativos ao tema. Depois, colheu-se a opinião do grupo - que será transmitida pelo Canal 4 inglês (em data posterior à elaboração deste texto). Segundo Fishkin, que já organizou outras sondagens semelhantes, a prática é encorajadora. Os consultados, afirma, costumam demonstrar seu apreço emocionado pelo fato de terem suas idéias consideradas com respeito pela primeira vez em suas vi- das. Sugestivo é o fato de que muitos dos presentes a esses encontros alteram pontos de vista anteriores tomados a partir de informações incompletas alimentadas por impulsos ou golpes de propaganda. Cita, como exemplo, o fato de que, após uma dessas sondagens, o número dos que achavam necessário mandar mais gente para a cadeia a fim de conter a criminalidade caiu de $57 \%$ para $38 \%$ enquanto subia de $36 \%$ para $50 \%$ o número dos que consideravam ser direito de uma pessoa manter-se em silêncio se interrogada pela polícia. Esse tipo de sondagem nada tem que o aproxime das práticas tradicionais consistentes na apresentação, aos sondados, de proposições rígidas previamente determinadas e que freqüentemente já conduzem à idéia que o pesquisador (quase sempre a imprensa e, mais especificamente, a televisão) quer ver aprovada. Com a sondagem-seminário, a já reconhecida ditadura da opinião pública sondada poderia cair.

Fishkin não parece considerar inviável a idéia de um governo gerenciado pelas decisões de pequenos grupos de cidadãos escolhidos ao acaso e que tomariam decisões públicas importantes através de conselhos deliberativos. Dificilmente esse sistema seria pior que o atual, em que - pelo menos no caso do Brasil - um pequeno grupo de pessoas é escolhido ao acaso nas eleições alimentadas a dinheiro e troca de favores para, em seguida, decidir, em conselhos supostamente deliberativos, medidas de alcance nacional. Talvez a democracia delibe-rativa seja impraticável como forma organi-zativa em grande escala. E, quase certamente, até sobre esse seminário-deliberativo será possível exercer fortes pressões lobistas sem qualquer preocupação coletiva. Mas Fishkin não acha impossível que representações microcósmicas da coletividade possam apresentar a essa mesma coletividade, através da televisão, recomendações que orientem a decisão da maioria. Uma utopia, talvez. Em todo caso, mais uma tentativa de empowerment da sociedade civil, de algum modo já posta em prática no Brasil em cidades administradas pelo Partido dos Tabalhadores, que utiliza a tática do “orçamento participativo" como versão do semi-
8 James Fishkin, The Voice of the People, Yale University Press, 1996. 
nário-deliberativo capaz de fazer a ponte entre a democracia representativa e a democracia direta. Essa prática é há muito conhecida por empresas interessadas em vender algo que os consumidores queiram comprar e por organismos como os universitários quando conseguem mostrar-se permeáveis a seus próprios ensinamentos teóricos... No domínio das práticas culturais dos jovens, programas brasileiros de televisão a eles dedicados (9) ensaiam intuitiva e canhestramente há algum tempo essa mesma fórmula, certamente sem que seus promotores tenham lido sobre a pós-modernidade ou ouvido falar das teorias do semináriodeliberativo. Como as televisões não estão efetivamente interessadas em escutar os jovens, nelas o processo é, antes, um simulacro de informação-debate-deliberação: as personalidades convidadas - geralmente artistas da música ou da própria televisão, esportistas, eventualmente um político abrem-se a todo tipo de perguntas dos jovens, das que investigam sua vida pública às que se voltam para sua intimidade. Mas tudo tem de se passar em uma hora, interrompida pelos blocos comerciais, sem que se possa recorrer a quem conteste ou confronte as opiniões manifestadas na arena virtual por convidados-personalidades e pelos perguntadores-pessoas-comuns. A cena desses jovens, universitários ou quase, fascinados pela magia da pergunta franca e da resposta supostamente idem, feita sob o olhar espelhado da televisão, pode à primeira vista desencantar aqueles que passaram pela experiência estudantil de 68. Vista sob as luzes da reflexão pós-moderna, ela é bem menos aflitiva, ainda mais se encarada como sinal de uma tendência passível de abrir-se a experiências mais consistentes.

Essa nova cultura política embrionária não parece constituir-se apenas por grupos de jovens individualistas, voltados para o próprio umbigo e que procuram apenas um relacionamento hedonista com o mundo. Novas pesquisas (10) do Départment des Études et de la Prospective do Ministério da Cultura francês sobre a freqüentação aos locais de espetáculo e de patrimônio e a imagem deles feitas pelos jovens franceses permitem a seu coordenador, Jean-Michel Guy, detectar, entre as várias relações identitárias dos jovens, uma que ele denomina identidade cidadã. Seus dados apontam para o fato de que a maioria dos jovens faz, de suas práticas culturais, representações que garantam sua integração futura no mundo dos adultos e ao mesmo tempo lhes proporcionem a sensação de serem reconhecidos como membros de uma coletividade mais ampla. A sondagem mostra que o desejo de ir a um espetáculo histórico ou visitar um monumento histórico é mais forte que a freqüência efetiva a esses locais. Mas do conjunto das respostas seria possível concluir que os jovens pretendem demonstrar, assim, não serem hostis às práticas consagradas pela coletividade embora estas não lhes interessem de imediato. J.-M. Guy conclui, acertadamente ao que tudo indica, que a vontade de não desconhecer o patrimônio cultural da sociedade deve ser vista como uma extensão do apego dos jovens às noções de família e de coesão social observadas, se não em todos, pelo menos na maioria deles (11).

Essa identidade cidadã dos jovens emergiu claramente à superfície do cenário político brasileiro por ocasião das manifestações populares a favor do impeachment do primeiro presidente eleito após o final da ditadura militar de 64, Collor de Melo. Não é improvável que sem o peso da presença dos jovens - que não deixaram de exibir simultaneamente sua identidade etária, visível nos rostos pintados ao modo das torcidas esportivas tal como difundido pela TV para o resto do mundo a partir da Inglaterra-o impeachment não tivesse recebido a aprovação parlamentar. A identidade cidadã detectada através das práticas culturais na França parece ter um caráter perene, enquanto a brasileira surge como episódica (numa leitura reforçada pelo fato de que, aqui, inexiste o forte apego francês ao patrimônio cultural nacional). São ambas, porém, índices não apenas da importância atribuída pelos jovens ao estar junto como de sua preocupação com o coletivo - em outras palavras, com o político.

Há, sem dúvida, jovens e jovens: a identidade etária, como observou Pierre 
Bourdieu, é uma ficção ou, em todo caso, um constructo sociológico, não um dado biológico. Se há jovens que pelo menos prevêem sua inserção no quadro de valores afirmados pela coletividade, há outros para os quais essa inclusão é irrelevante ou impossível. Uma das tribos da identidade etária no Brasil tem sido, há algum tempo, a dos pichadores de prédios e... monumentos históricos. Outras tribos, ainda menos integradoras, são as dos passadores de droga, trombadinhas e assaltantes soft ou hard observadas a distância como eventual $e$, às vezes, inescapável opção futura pelo grande número de jovens que consideram o trabalho, quando conseguem encontrá-lo, nada mais do que uma forma de escravidão (12), não de realização pessoal ou de construção coletiva, sem que se lhes possa negar razão. Esse quadro, numa sociedade como a brasileira, não tem, hoje, perspectivas risonhas: os riscos pelo exercício da atividade ilegal são mínimos e inexiste atividade legal que renda aos jovens infratores aquilo que obtêm à margem dos valores publicamente prezados. Como serão os jovens a pressionar fortemente o mercado de trabalho e como este mercado está se preparando para excluir a maioria desses jovens - mesmo que essa maioria, como dizem as pesquisas, hoje não consuma drogas nem beba álcool (a não ser "socialmente") -, não é difícil prever o embate próximo entre três culturas políticas: a institucional-delegacional, supostamente representativa, que em sua forma atual exclui as duas seguintes; a societal, ou deliberativa-imediata, que não chega a repudiar a primeira mas que não tem no momento qualquer canal de realização; e a marginal ou, a rigor, a anticultura política, oposta a ambas as anteriores e interessada apenas na preservação de localismos extremamente delimitados e agressivos. Reforçando a idéia de que há jovens e jovens e que a cultura política dos jovens de um dado território não é necessariamente compartida por outros jovens de outro território mesmo nesta época de globalização, dados do Mapa de Risco da Violência da Cidade de São Paulo (13) dizem que o grupo de moradores da cidade na faixa dos 20 aos 24 anos (exata- mente aquele da pesquisa na USP) é o que apresenta as maiores taxas de homicídio na cidade - principalmente quando esses moradores são os da periferia. Dificilmente se poderá falar numa identidade cidadã entre esses jovens ou entre aqueles norte-americanos envolvidos em estatísticas que apontam, para os últimos dez anos, um crescimento de $125 \%$ no número de garotas e moças presas por crimes violentos e de $67 \%$ no dos meninos adolescentes na mesma situação(14). Para estes, o que se propõe é o toque de recolher, quer dizer, a suspensão relativa e preliminar de seus direitos de cidadão.

Esta perspectiva sombria não elimina o traço mais fortemente simbólico da cultura política que é a decidida adesão dos jovens às práticas do estar junto, passível de constituir-se na base de novas tentativas de organização política, de uma nova cultura política. Mas, já que a entrada dos jovens para a cultura política parece dar-se hoje, de um modo ou de outro, pela porta da cultura, como mostra a pesquisa feita na USP (15), haveria algo a fazer em termos de uma política cultural que colaborasse para a fixação e ampliação desse estado de espírito? Os estudantes da USP foram perguntados a respeito do que esperavam da cultura. Dos ingressantes, menos de 5\% afirmaram desconhecer aquilo que a cultura pode lhes oferecer (16). Já entre os formandos a situação se alterou sensivelmente. Se mais de 50\% disseram esperar, de obras de cultura, apenas "prazer estético" (contra um índice de pouco mais de $10 \%$ entre os ingressantes, nesse quesito) -, o que pode ser um índice de maturidade cultural ao apontar para o abandono de um entendimento funcionalista da cultura,$- 30 \%$ deles, ou seis vezes mais que os ingressantes, disseram não saber o que esperar da cultura. Se tinham, quatro ou cinco anos antes, alguma idéia clara quanto ao que a cultura poderia lhes dar, a passagem pela universidade derrubou suas eventuais certezas. Isso pode ser positivo, se considerada a hipótese de que mais tarde, em suas vidas, esses jovens não mais tão jovens reconstruirão, por si mes-
12 Jane S. de Oliveira, "Traços Socioeconômicos do Alunato da ENCE", Rio de Janeiro, 1994, mimeo.

13 Elaborado pelo Centro de Estudos de Cultura Contemporânea, de São Paulo, para o Ministério da Justiça brasileiro.

14 Gilberto Dimenstein, "Os EUA Adotam Projeto 'Grande Brasil"', in Folha de S. Pau10, 4/8/96.

I5 Seja através dos cadernos culturais, dos centros culturais ou dos centros de recreação como os da Fundação Reedleen, que os mantêm primordialmente para os jovens ameaçados pelo toque de recolher em Nova York.

16 A metade disse esperar, da cultura, informação e aprimoramento, o que novamente está ligado ao fato de terem acabado de prestar um vestibular para o qual tinham de estar "culturalmente" preparados, isto é, informados, se quisessem ter chances de progressão econômica na vida, como as pessoas ainda costumam dizer e acreditar, ao lado destes, $35 \%$ disseram esperar, da cultura, apenas distração. 
mos e para si mesmos, um sentido para a cultura. Mas, conhecendo a tendência brasileira nesse campo, nãoé impossível que esses $30 \%$ não vejam nenhum sentido para a cultura e passem a olhá-la como o fazem muitos de seus contemporâneos mais velhos: algo supérfluo, ornamental, inútil, não raro nocivo. O fato de $30 \%$ dos jovens da maior universidade brasileira não saberem o que esperar da cultura pode ser um sinal de alarme. Pode ser que os jovens, como toda a sociedade, não saibam como retirar o que da cultura - problema de educação. E pode ser que a cultura que está por aí pouco ou nada de relevante esteja dizendo aos jovens. Como as orientações de valor para a cultura política são retiradas também da obra de cultura, embora não apenas dela, e como a cultura é aquilo que, no limite, une as pessoas, o horizonte fica duplamente turvo.

Mas não há no momento, no Brasil, uma política cultural que caminhe no sentido da tendência societária dos jovens (o que não os impede de providenciar, ou tentar providenciar, para si mesmos, aquilo de que sentem precisar). Ou que vá ao encontro de qualquer outra tendência juvenil, por falar nisso. O melhor que fazem as políticas existentes, as políticas culturais remanescentes, é apoiar práticas culturais que podem talvez, mas não necessariamente, servir de pretexto indireto para a cultura societária. Políticas culturais como a francesa, assim como eram planejadas e executadas pelo menos até o enxugamento do estado iniciado já no período Mitterrand e acentuado com a ascensão do neoliberalismo pleno de $\mathbf{J}$. Chirac, teriam condições de contribuir para a construção do nicho da identidade cidadã dos jovens, do espaço de sua cultura política. Não se vislumbra com facilidade, porém, a possibilidade dessas políticas no Brasil neoliberal de hoje. As sondagens fazem prever para breve, graças à cultura e, em segundo plano, ao esporte, uma visibilidade social maior dos jovens de "extração popular”. Em que cultura emergirão? Que cultura trarão? Para qual cultura política convergirá essa cultura?

A maior lacuna das políticas culturais de países como o Brasil continua a ser aquela aberta pela omissão da instância pública diante dos meios de comunicação, em particular a TV. Administrações sucessivas, de diferentes colorações ideológicas, encenam um apoio paternalista e episódico às culturas tradicionais, de origem elitista (se é que esse termo ainda tem curso), para desviar a atenção geral do domínio da exploração comercial das ondas eletrônicas no qual não querem tocar por conveniência politiqueira, quando não mais baixamente econômica. Mesmo que as teses de J. Fishkin soem irrealistas, têm pelo menos o mérito de chamar a atenção, mais uma vez, para o papel que a televisão pode representar na construção de uma revigorada cultura política. A atual cultura política disseminada pela televisão, no Brasil, é aquela institucionaldelegacional, que ela propaga em sua condição de mais refinado exemplo de intelectual orgânico de todos os tempos: intelectual orgânico do poder instalado, seja qual for. Os governos acomodam-se, todos, a esse traço estrutural da televisão por eles mesmos criado e alimentado - mesmo aqueles de origem "esclarecida", como a atual administração brasileira. E aquilo com que essa cultura alimenta um país são as respostas desinformadas que o público (não os cidadãos, ou o povo) é treinado para devolver e tende a devolver quando chamado a manifestar sua "opinião" em eleições formais e sondagens que orientam as urnas nas vésperas da votação. Uma política para a televisão, como, repetindo, tem a França, colocase como vital - tanto mais que os estudantes "populares" da ENCE-Rio reconhecem passar boa parte de seu tempo livre em casa vendo TV (e apesar de os estudantes de classe média da USP rejeitarem amplamente a TV atual). E essa política é ainda mais vital, se isso pode existir, quando se observa que a maior parte do material levado ao ar pela televisão aberta, em telefilmes e noticiários, corrói sistematicamente a cultura política em todos os sentidos dessa expressão. Enquanto esse terreno não for ocupado pela reflexão pública, continuaremos sem cultura política, sem uma cultura que torne possível a vida na pólis, na cidade, na sociedade. Continuaremos com a bárbarie. 


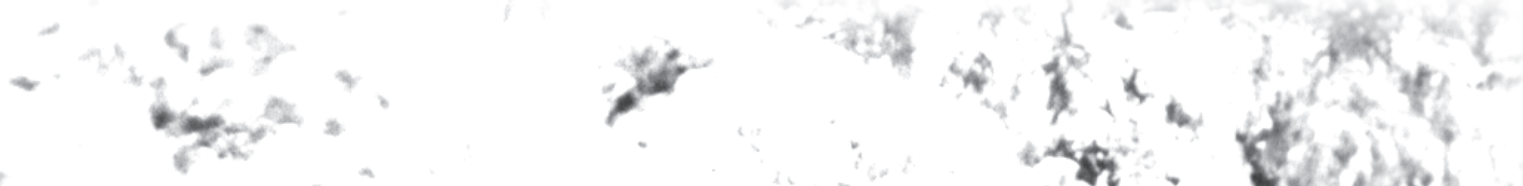

$$
\begin{aligned}
& \text { ats }
\end{aligned}
$$

F

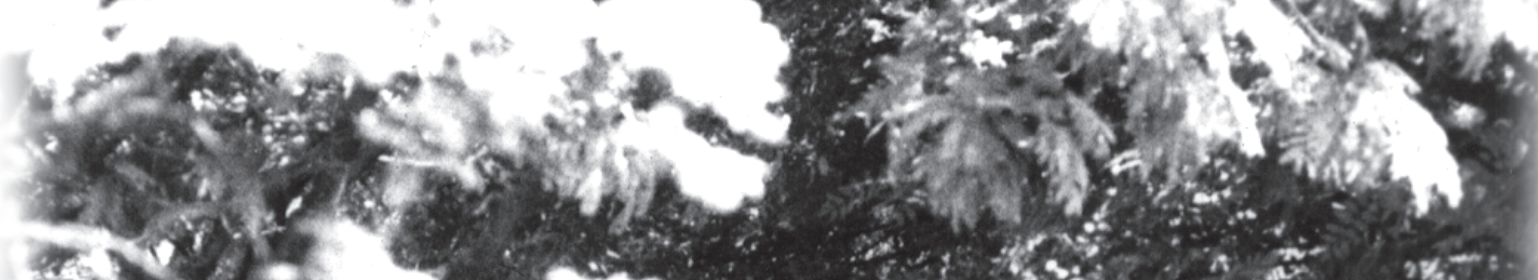
(1) if

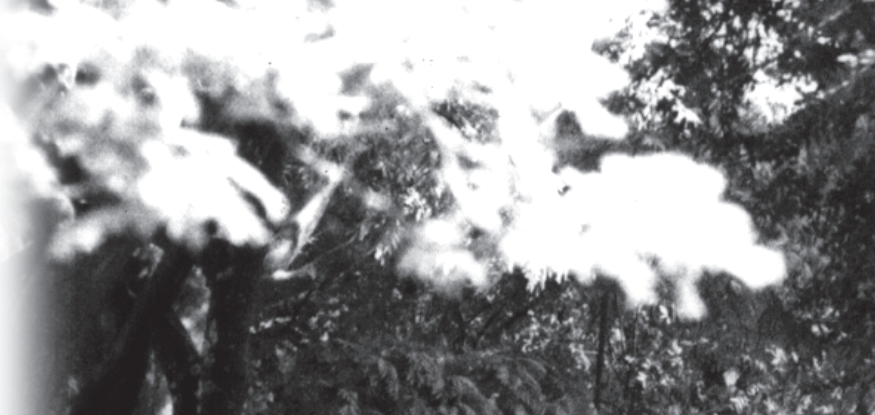

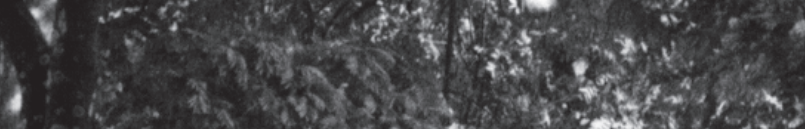

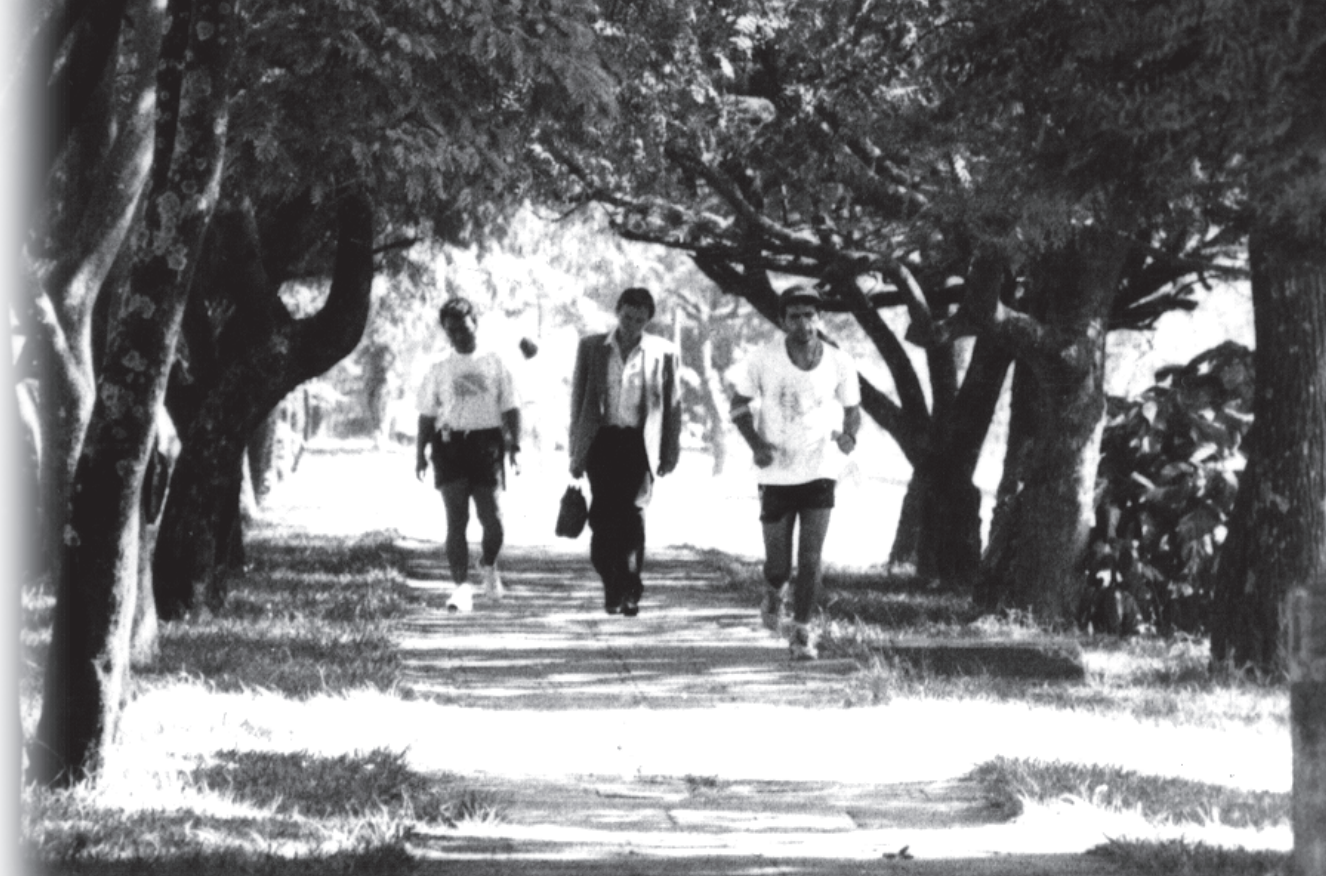

